\title{
Comparison of hydration and nutritional status between young and elderly hemodialysis patients through bioimpedance analysis
}

\author{
Jung Eun Lee ${ }^{1,2}$ \\ In Young $\mathrm{JO}^{3}$ \\ Song Mi Lee ${ }^{3}$ \\ Woo Jeong $\mathrm{Kim}^{3}$ \\ Hoon Young Choi ${ }^{2,4}$ \\ Sung Kyu $\mathrm{Ha}^{4}$ \\ Hyung Jong Kim ${ }^{5}$ \\ Hyeong Cheon Park ${ }^{2,4}$ \\ 'Department of Internal Medicine, \\ Yongin Severance Hospital, Yonsei \\ University College of Medicine, \\ ${ }^{2}$ Severance Institute for Vascular and \\ Metabolic Research, Yonsei University \\ College of Medicine, ${ }^{3}$ Department \\ of Nutrition Services, Gangnam \\ Severance Hospital, ${ }^{4}$ Department of \\ Internal Medicine, Gangnam Severance \\ Hospital, Yonsei University College \\ of Medicine, Seoul, ${ }^{5}$ Department of \\ Internal Medicine, CHA Bundang \\ Medical Center, CHA University, \\ Seongnam, Korea
}

Correspondence: Hyeong Cheon Park Department of Internal Medicine, Gangnam Severance Hospital, Yonsei University College of Medicine, 2II Eonju-ro, Gangnam-gu, Seoul, |35-720, Korea

$\mathrm{Tel}+82220193310$

Fax +82 234633882

Email amp97@yuhs.ac

\section{Hyung Jong Kim}

Department of Internal Medicine, Bundang CHA Medical Center, CHA University, 59 Yatap-ro, Bundang-gu, Seongnam-si, Gyeonggi-do, 463-7I2, Korea

Tel +82317805895

Fax +82 3I 780598 I

Email khj04@cha.ac.kr
This article was published in the following Dove Press journal:

Clinical Interventions in Aging

13 August 2015

Number of times this article has been viewed

Background: The number of elderly people on dialysis is increasing rapidly. Fluid overload and malnutrition status are serious problems in elderly dialysis patients. We aimed to compare the hydration and nutritional status through bioimpedance analysis (BIA) between young and elderly hemodialysis (HD) patients and to analyze risk factors related to fluid overload and malnutrition status in these patients.

Method: We conducted a cross-sectional study, in which $82 \mathrm{HD}$ (males 42, mean age $58.7 \pm 12.9$ years) patients were enrolled. We collected different types of data: laboratory data, such as serum creatinine, albumin, total iron-binding capacity, hemoglobin, total cholesterol; anthropometric data, such as hand grip strength (HGS); BIA data, such as intracellular water, skeletal muscle mass, body cell mass, bone mineral content, phase angle ( $\mathrm{PhA})$, extra cellular water (ECW)/total body water (TBW) ratio; and malnutrition-inflammation score (MIS), which is a traditional nutritional parameter for dialysis patients. All patients were stratified into two groups according to their age: young $(<65$ years $[n=54])$ and elderly $(\geq 65$ years $[n=28])$.

Results: Total iron-binding capacity and HGS were significantly lower in elderly HD patients than in young HD patients (198.9 $\pm 35.6 \mathrm{vs} 221.4 \pm 52.1 \mathrm{mcg} / \mathrm{dL}$; and $22.4 \pm 10.3 \mathrm{vs} 36.4 \pm 23.2 \mathrm{~kg}$, respectively) $(P<0.05)$. Also, intracellular water and $\mathrm{PhA}$ measured by BIA were significantly lower (18.3 \pm 4.0 vs $20.3 \pm 4.2 \mathrm{~L}[P=0.043]$; and $4.0 \pm 1.0$ vs $4.9 \pm 1.2^{\circ}[P=0.002]$, respectively), and ECW/TBW were higher in elderly HD patients $(0.40 \pm 0.01$ vs $0.39 \pm 0.01[P=0.001])$. ECW/TBW was positively associated with age $(P<0.001)$ and the presence of diabetes $(P<0.001)$ and was negatively associated with sex $(P=0.001)$, albumin $(P<0.001)$, urine volume $(P=0.042)$, HGS $(P<0.001)$, and PhA by BIA $(P<0.001)$. MIS was negatively related to sex $(P=0.001)$, albumin $(P<0.001)$, HGS $(P=0.001)$, and $\mathrm{PhA}(P<0.001)$ in HD patients. On multivariate analysis, older age $(P=0.031)$, the presence of diabetes $(P=0.035)$, and decreased $\mathrm{PhA}(P<0.001)$ were independent risk factors for increased $\mathrm{ECW} / \mathrm{TBW}$, representative of fluid overload status, whereas only decreased $\mathrm{PhA}(P=0.008)$ was a significant factor for MIS, representative of malnutrition status in these HD patients.

Conclusion: We found that fluid overload and malnutrition status were more common in elderly HD patients compared with young HD patients. PhA was a significant independent factor in fluid overload status and malnutrition in these HD patients. Thus, our results indicated that $\mathrm{PhA}$ assessed by BIA might be a clinically useful method for assessing nutritional and hydration status in elderly HD patients.

Keywords: fluid overload, malnutrition, hemodialysis, elderly patients, body composition

\section{Introduction}

Elderly patients account for an increasing proportion of patients on renal replacement therapy worldwide. ${ }^{1}$ Therefore, there has been a growing interest in elderly 
end-stage renal disease (ESRD) patients. Chronic volume overload can induce hypertension, left ventricular hypertrophy, heart failure, pulmonary edema, and even increase the mortality risk in hemodialysis (HD) patients..$^{2-5}$ On the contrary, chronic volume deficit status can induce intradialytic hypotension, muscle cramps, and shock. ${ }^{6}$ Accordingly, to maintain proper volume status in ESRD patients, it is important to determine the optimal dry weight. Bioelectric impedance analysis (BIA) is known to accurately measure the nutritional status as well as water distribution in the individual by assessing body composition..$^{7-9}$ In general, as individuals age, fat-free mass (FFM), including muscle mass, bone mass, and body water, decrease and fat mass increases due to the increase in visceral fat mass. ${ }^{10}$ Further, the loss of muscle mass and gains in fat tissue result in increased extracellular water (ECW)/total body water (TBW) ratios, in other words, fluid overload status, in elderly dialysis patients. ${ }^{11}$ Such changes in body composition and nutritional status in elderly HD patients may be important factors in determining the optimal dry weight. However, there has been little research on comparative analysis of body composition or of nutritional status between young and elderly HD patients so far. Therefore, we compared the hydration and nutritional status between young and elderly HD patients through BIA and various anthropometric methods, and analyzed risk factors related to fluid overload and malnutrition status in these patients.

\section{Subjects and methods Study design and patients}

We conducted a cross-sectional observational comparative study to evaluate the hydration and nutritional status in elderly and young HD patients. This study was approved by the Institutional Review Board for human research at Gangnam Severance Hospital (approval number 3-2013-0039), and all participants provided written informed consent prior to study enrollment. A total of 90 patients on chronic HD (46 males, mean age $58.8 \pm 11.3$ years), from dialysis units at Gangnam Severance Hospital, Yongin Severance Hospital, and CHA Hospital, were enrolled in this study between March and May 2013. All participants aged 18 years or older had been on HD for $\geq 3$ months (mean dialysis duration: 50 months). Exclusion criteria included inability to communicate with examiners, acute illness within the previous 3 months, malignancy, pulmonary edema, liver cirrhosis with ascites, and New York Heart Association (NYHA) III or IV congestive heart failure. Thus, we excluded eight patients (three patients with severe heart failure, two patients with acute illness, and three patients with malignancy) and collected the data for 82 patients. We analyzed baseline clinical data, such as age, sex, comorbidity of diabetes or hypertension, and blood pressure. The actual height and body weight on the day of assessment were used. The causes of ESRD were diabetes $(n=42)$, hypertension $(n=29)$, glomerulonephritis $(n=6)$, polycystic kidney disease $(\mathrm{n}=3)$, and unknown $(\mathrm{n}=2)$. All patients underwent regular dialysis for 3.5-4 hours, three times per week. The efficiency of the dialysis was assessed based on the delivered dose of dialysis $\mathrm{spKt} / \mathrm{V}_{\text {urea }}$ using the natural logarithm formula of Daugirdas II. ${ }^{12}$ Urine output was expressed as $\mathrm{mL} / 24 \mathrm{~h}$.

\section{Laboratory data}

Baseline biochemical parameters, including hemoglobin, total iron-binding capacity (TIBC), creatinine, calcium, phosphate, albumin, C-reactive protein (CRP), and lipid profiles, were determined before the dialysis session. All laboratory parameters were measured using automated and standardized methods.

\section{Anthropometric data}

We also measured anthropometric data, such as body mass index (BMI), mid-arm circumference (MAC), mid-arm muscle circumference (MAMC), and triceps skinfold thickness (TSF). MAC was measured by a stretchable measuring tape, TSF was measured using skinfold calipers, and MAMC was calculated as

$$
\mathrm{MAMC}=\operatorname{MAC}(\mathrm{cm})-3.14 \times \operatorname{TSF}(\mathrm{mm}) / 10 .
$$

Hand grip strength (HGS) was measured using a Jamar ${ }^{\circledR}$ Hydraulic Hand Dynamometer (Sammons Preston Rolyan, Chicago, IL, USA) after the dialysis session. HGS was measured in the dominant arm. If a patient had an arteriovenous fistula, HGS was measured in the arm without the arteriovenous fistula, regardless of whether it was the dominant arm. The HGS measurement was repeated thrice in a sitting position using the dynamometer, in kilogram units. The maximum grip strength value among all measurements was used in the study.

\section{Assessment of nutritional status}

The malnutrition-inflammation score (MIS) was used to assess protein energy wasting. ${ }^{13}$ The MIS comprises seven components of the Subjective Global Assessment (weight change, dietary intake, gastrointestinal symptoms, functional capacity, comorbidity, fat store, and muscle wasting) and three additional components (BMI, serum albumin, 
and TIBC). Each component of the MIS has four levels of severity ranging from 0 (normal) to 3 (severely abnormal). The sum of all ten MIS components ranges from 0 (normal) to 30 (severely malnourished); a higher score reflects more severe malnutrition and inflammation.

\section{Body composition assessment}

We measured body composition through BIA (InBody S10; Biospace, Seoul, South Korea). According to clinical applications of body composition assessment, we performed BIA within 30 minutes of dialysis. ${ }^{14}$ A pair of electrodes was placed on the surface of the thumb, fingers of the hand, and ball of the foot and heel. With these electrodes, microprocessor-controlled switches and an impedance analyzer were operated, and segmental resistance was measured at six frequencies $(1,5,50,250,500$, and 1,000 kHz). Thus, a set of 30 segmental resistances was measured in each individual. The parameters assessed by BIA were intracellular water (ICW), ECW, TBW, protein, mineral, FFM, skeletal lean mass, skeletal muscle mass (SMM), body cell mass (BCM), and bone mineral content (BMC). The ECW/TBW and TBW/FFM were subsequently calculated from the sum of each segment, using the equations in the BIA software. Phase angle $(\mathrm{PhA})$ was calculated from reactance $(\mathrm{Xc})$ and $\mathrm{R}$ (resistance), according to the formula:

$$
\operatorname{PhA}\left(^{\circ}\right)=\mathrm{Xc} / \mathrm{R} \times 180^{\circ} / \pi .
$$

\section{Statistical analysis}

Continuous variables were presented as mean \pm standard deviation, and categorical variables as number and percentage. Baseline characteristics of the patients were compared using the Student's $t$-test for continuous variables and $\chi^{2}$ test for categorical variables. We confirmed normality assumption through the Shapiro-Wilk test. As a result, variables on HD duration, cholesterol level, high-density lipid-cholesterol (HDL-C), and HGS of female patients showed abnormal distribution. Consequently, we analyzed Mann-Whitney $U$-test for these variables. Pearson's correlation analysis was performed to estimate the correlation between age and various parameters of nutritional and hydration status. We performed univariate and multivariate linear regression analyses to determine the association between clinical variables and hydration or nutritional status in all HD patients. We multiplied 100 by ECW/TBW because the ECW/TBW difference was minute on univariate and multivariate analyses. Also, we analyzed post hoc power analysis because the sample size was rather limited and the ECW/TBW difference was very small. Values of $P<0.05$ were considered to indicate statistical significance. Statistical analysis was performed using SPSS for Windows Version 20.0 (IBM Corp., Armonk, NY, USA).

\section{Results}

\section{Baseline characteristics}

Forty-two (51.2\%) study subjects were males. Their ages ranged from 29 to 85 years (mean age $58.7 \pm 12.9$ years). Fortyseven $(57.3 \%)$ study subjects were diabetic. They underwent HD for a median period of 48 months (range 4-260 months). Sixteen patients $(20.0 \%)$ were smokers. Forty-six $(56.1 \%)$ patients took diuretics, 39 (47.5\%) patients received angiotensin-converting enzyme inhibitors or angiotensin-II receptor blockers, and $22(26.8 \%)$ patients took statin/fibrate medication. Twenty-five (30.5\%) patients had previous history of cardiovascular disease. Patients were stratified as young $(<65$ years $[n=54])$ and elderly $(\geq 65$ years $[n=28])$ according to their age. Serum TIBC, creatinine, and triglyceride were significantly lower in elderly HD patients than in young HD patients (198.9 \pm 35.6 vs $221.4 \pm 52.1 \mu \mathrm{g} / \mathrm{dL} ; 8.1 \pm 3.1$ vs $9.6 \pm 3.2 \mathrm{mg} / \mathrm{dL}$; and $80.5 \pm 49.4$ vs $121.2 \pm 80.9 \mathrm{mg} / \mathrm{dL}$, respectively) $(P<0.05)$. The HDL-C level in elderly $\mathrm{HD}$ patients was higher than that in young HD patients (45.4 \pm 14.9 vs $38.0 \pm 12.3 \mathrm{mg} / \mathrm{dL})(P=0.030)$ (Table 1$)$. HGS in elderly patients was lower than that in young HD patients (for males, this was $28.2 \pm 10.6$ vs $44.8 \pm 25.6 \mathrm{~kg}[P=0.046]$ and for females, was $17.9 \pm 7.8$ vs $26.6 \pm 15.4 \mathrm{~kg}[P=0.030]$ ). However, MIS (representative of nutritional status) in elderly HD patients was higher than in young HD patients but did not show significant differences (Table 2). No significant differences were observed in any other parameters between elderly and young HD patients.

\section{Comparison of parameters derived from BIA}

TBW in elderly HD patients was lower than that in young HD patients but did not show significant group differences. ECW did not show significant differences between the two groups, but ICW in elderly HD patients was significantly lower than that in young HD patients $(18.3 \pm 4.0$ vs $20.3 \pm 4.2 \mathrm{~L})$ $(P=0.043)$. ECW/TBW $(0.40 \pm 0.01$ vs $0.39 \pm 0.01)(P=0.001)$ and TBW/FFM $(74.0 \pm 0.4$ vs $73.7 \pm 0.4)(P=0.004)$ in elderly HD patients were significantly higher than those in young HD patients. Protein and mineral measured by BIA were significantly lower in elderly HD patients compared with young HD patients (for protein, this was $7.9 \pm 1.7$ vs $8.7 \pm 1.8 \mathrm{~kg}$ 
Table I Baseline characteristics of the patients according to age (demographic and laboratory data)

\begin{tabular}{|c|c|c|c|c|}
\hline & Total $(n=82)$ & Age $\geq 65$ years $(n=28)$ & Age $<65$ years $(n=54)$ & $P$-value \\
\hline Age (years) & $58.7 \pm 12.9$ & $72.5 \pm 4.9$ & $51.5 \pm 9.4$ & $<0.00 \mathrm{I}$ \\
\hline Sex (male), n (\%) & $42(5 । .2)$ & $13(46.4)$ & $29(53.7)$ & 0.532 \\
\hline HD duration (months) & $48.8 \pm 43.4$ & $48.4 \pm 51.4$ & $49.0 \pm 39.1$ & 0.660 \\
\hline DM, n (\%) & $47(57.3)$ & $14(50.0)$ & $33(61.1)$ & 0.335 \\
\hline Smokers, n (\%) & $16(20.0)$ & $5(17.8)$ & $9(20.3)$ & 0.384 \\
\hline Diuretics, n (\%) & $46(56 . I)$ & I4 (50.0) & $32(59.2)$ & 0.234 \\
\hline ACEi or ARB use, n (\%) & $39(47.5)$ & $13(46.4)$ & $26(48.1)$ & 0.552 \\
\hline Statin/fibrate use, n (\%) & $22(26.8)$ & $7(25.0)$ & $15(27.7)$ & 0.320 \\
\hline CVD Hx, n (\%) & $25(30.5)$ & $9(32.1)$ & $16(29.6)$ & 0.102 \\
\hline $\mathrm{SBP}(\mathrm{mmHg})$ & $144.4 \pm 22.2$ & $144.0 \pm 22.1$ & $144.6 \pm 22.3$ & 0.744 \\
\hline Hemoglobin $(g / d L)$ & $10.3 \pm 1.0$ & $10.1 \pm 1.0$ & $10.4 \pm 1.0$ & 0.667 \\
\hline TIBC $(\mathrm{mcg} / \mathrm{dL})$ & $213.8 \pm 48.1$ & $198.9 \pm 35.6$ & $221.4 \pm 52.1$ & 0.024 \\
\hline Creatinine (mg/dL) & $9.1 \pm 3.3$ & $8.1 \pm 3.1$ & $9.6 \pm 3.2$ & 0.033 \\
\hline Calcium (mg/dL) & $8.8 \pm 0.6$ & $8.8 \pm 0.7$ & $8.9 \pm 0.5$ & 0.748 \\
\hline Phosphate (mg/dL) & $4.6 \pm 1.4$ & $4.2 \pm 1.1$ & $4.8 \pm 1.5$ & $0.06 \mathrm{I}$ \\
\hline Albumin (g/dL) & $3.9 \pm 0.4$ & $3.8 \pm 0.4$ & $3.9 \pm 0.3$ & 0.075 \\
\hline CRP $(\mathrm{mg} / \mathrm{dL})$ & $1.46 \pm 0.50$ & $1.55 \pm 1.50$ & $1.10 \pm 1.06$ & 0.157 \\
\hline Cholesterol (mg/dL) & $147.3 \pm 33.7$ & $152.5 \pm 25.7$ & $144.6 \pm 37.1$ & 0.114 \\
\hline Triglyceride (mg/dL) & $107.3 \pm 74.0$ & $80.5 \pm 49.4$ & $121.2 \pm 80.9$ & 0.002 \\
\hline HDL-C (mg/dL) & $40.5 \pm 13.6$ & $45.4 \pm 14.9$ & $38.0 \pm 12.3$ & 0.030 \\
\hline LDL-C (mg/dL) & $80.8 \pm 27.3$ & $85.0 \pm 27.0$ & $78.5 \pm 27.5$ & 0.304 \\
\hline Urine output (mL/day) & $405.0 \pm 358.9$ & $420.0 \pm 431.5$ & $397.5 \pm 329.0$ & 0.150 \\
\hline $\mathrm{spK} t / \mathrm{V}$ & $1.21 \pm 0.19$ & $1.25 \pm 0.17$ & $1.19 \pm 0.19$ & 0.304 \\
\hline
\end{tabular}

Note: Variables are expressed as mean \pm SD, unless otherwise stated.

Abbreviations: ACEi, angiotensin converting enzyme inhibitor; ARB, angiotensinogen receptor blocker; CRP, C-reactive protein; CVD Hx, cardiovascular disease history; DM, diabetes mellitus; spKt/V, single-pool Kt/V; HD, hemodialysis; HDL-C, high-density lipid-cholesterol; LDL-C, low-density lipid-cholesterol; SBP, systolic blood pressure; TIBC, total iron-binding capacity.

$[P=0.043]$ and for mineral, was $2.8 \pm 0.6 \mathrm{vs} 3.1 \pm 0.5 \mathrm{~kg}$ $[P=0.041])$. SMM, BCM, BMC, and PhA were also decreased in elderly HD patients $(21.8 \pm 5.3 \mathrm{vs} 24.4 \pm 5.5 \mathrm{~kg}$ $[P=0.043] ; 26.1 \pm 5.8$ vs $29.0 \pm .6 .0 \mathrm{~kg}[P=0.044] ; 2.3 \pm 0.5$ vs $2.5 \pm 0.4 \mathrm{~kg}[P=0.043]$; and $4.0 \pm 1.0$ vs $4.9 \pm 1.2^{\circ}[P=0.002]$, respectively). No significant differences were observed in any other BIA parameters between elderly and young HD patients (Table 3).

Table 2 Baseline characteristics of the patients according to age (anthropometric data)

\begin{tabular}{lllll}
\hline & $\begin{array}{l}\text { Total } \\
(\mathbf{n}=\mathbf{8 2})\end{array}$ & $\begin{array}{l}\text { Age } \geq \mathbf{6 5} \text { years } \\
(\mathbf{n}=\mathbf{2 8})\end{array}$ & $\begin{array}{l}\text { Age }<\mathbf{6 5} \text { years } \\
(\mathbf{n}=\mathbf{5 4})\end{array}$ & $\boldsymbol{P}$-value \\
\hline BMI $\left(\mathrm{Kg} / \mathrm{m}^{2}\right)$ & $22.9 \pm 3.5$ & $23.0 \pm 2.6$ & $22.8 \pm 4.0$ & 0.778 \\
MAC $(\mathrm{cm})$ & $27.1 \pm 3.5$ & $26.4 \pm 2.3$ & $27.6 \pm 3.9$ & 0.091 \\
MAMC $(\mathrm{cm})$ & $21.5 \pm 4.2$ & $21.0 \pm 2.7$ & $21.7 \pm 4.8$ & 0.385 \\
TSF $(\mathrm{mm})$ & $16.8 \pm 6.4$ & $17.2 \pm 5.9$ & $16.7 \pm 6.7$ & 0.743 \\
HGS $(\mathrm{kg})$ & & & & \\
$\quad$ Male & $40.0 \pm 23.4$ & $28.2 \pm 10.6$ & $44.8 \pm 25.6$ & 0.046 \\
$\quad$ Female & $23.3 \pm 13.6$ & $17.9 \pm 7.8$ & $26.6 \pm 15.4$ & 0.030 \\
MIS & $5.0 \pm 2.8$ & $5.5 \pm 2.2$ & $4.8 \pm 3.0$ & 0.089 \\
\hline
\end{tabular}

Note: All variables are expressed as mean \pm SD.

Abbreviations: BMI, body mass index; HGS, hand grip strength; MAC, midarm circumference; MAMC, mid-arm muscle circumference; MIS, malnutritioninflammation score; SD, standard deviation; TSF, triceps skinfold.

\section{Independent risk factors associated with hydration and nutritional status in HD patients}

Age was negatively correlated with HGS $(r=-0.443$, $P<0.001), \operatorname{PhA}(r=-0.481, P<0.001)$, and $\mathrm{BCM}(r=-0.330$, $P=0.003)$, and it was positively correlated with $\mathrm{ECW} /$ TBW ( $r=0.503, P<0.001)$ (Figure 1). Univariate analysis showed that age $(\beta=0.054,95 \%$ confidence interval $[\mathrm{CI}]$ : 0.033 to $0.075, P<0.001)$, $\operatorname{sex}(\beta=-1.051,95 \% \mathrm{CI}:-1.630$ to $-0.472, P=0.001)$, the presence of diabetes $(\beta=1.137,95 \%$ CI: 0.560 to $1.714, P<0.001)$, albumin $(\beta=-1.531,95 \%$ CI: -2.311 to $-0.752, P<0.001)$, urine volume $(\beta=-0.002$, 95\% CI: -0.007 to $-0.005, P=0.042)$, HGS $(\beta=-0.034$, 95\% CI: -0.048 to $-0.020, P<0.001)$, and $\mathrm{PhA}$ by BIA $(\beta=-1.067,95 \%$ CI: -1.164 to $-0.971, P<0.001)$ were associated with ECW/TBW. Sex $(\beta=-1.929,95 \% \mathrm{CI}:-3.078$ to $-0.779, P=0.001)$, albumin $(\beta=-3.188,95 \% \mathrm{CI}:-4.708$ to $-1.669, P<0.001)$, HGS $(\beta=-0.049,95 \%$ CI: -0.078 to $-0.020, P=0.001)$, and $\mathrm{PhA}(\beta=-1.255,95 \%$ CI: -1.675 to $-0.835, P<0.001)$ were associated with MIS in HD patients. On multivariate analysis, age $(\beta=0.012,95 \% \mathrm{CI}$ : 0.001 to $0.023, P=0.031$ ), the presence of diabetes $(\beta=0.294$, 
Table 3 Comparison of parameters derived from bioimpedance analysis

\begin{tabular}{lllll}
\hline & $\begin{array}{l}\text { Total } \\
(\mathbf{n}=\mathbf{8 2})\end{array}$ & $\begin{array}{l}\text { Age } \geq \mathbf{6 5} \text { years } \\
(\mathbf{n}=\mathbf{2 8})\end{array}$ & $\begin{array}{l}\text { Age }<\mathbf{6 5} \text { years } \\
(\mathbf{n}=\mathbf{5 4})\end{array}$ & P-value \\
\hline TBW $(\mathrm{L})$ & $32.3 \pm 6.7$ & $30.5 \pm 6.6$ & $33.3 \pm 6.7$ & 0.082 \\
ECW (L) & $12.7 \pm 2.5$ & $12.3 \pm 2.5$ & $13.0 \pm 2.5$ & 0.221 \\
ICW (L) & $19.6 \pm 4.3$ & $18.3 \pm 4.0$ & $20.3 \pm 4.2$ & 0.043 \\
ECW/TBW & $0.39 \pm 0.01$ & $0.40 \pm 0.01$ & $0.39 \pm 0.01$ & $0.00 \mathrm{I}$ \\
Protein (kg) & $8.4 \pm 1.8$ & $7.9 \pm 1.7$ & $8.7 \pm 1.8$ & 0.043 \\
Mineral (kg) & $3.0 \pm 0.6$ & $2.8 \pm 0.6$ & $3.1 \pm 0.5$ & 0.041 \\
Fat mass (kg) & $17.1 \pm 8.5$ & $18.1 \pm 7.3$ & $16.6 \pm 9.0$ & 0.405 \\
FFM (kg) & $43.8 \pm 9.1$ & $41.2 \pm 8.9$ & $45.1 \pm 8.9$ & 0.069 \\
SLM (kg) & $41.3 \pm 8.7$ & $38.9 \pm 8.4$ & $42.6 \pm 8.6$ & 0.072 \\
SMM (kg) & $23.5 \pm 5.5$ & $21.8 \pm 5.3$ & $24.4 \pm 5.5$ & 0.043 \\
BCM (kg) & $28.0 \pm 6.1$ & $26.1 \pm 5.8$ & $29.0 \pm 6.0$ & 0.044 \\
BMC (kg) & $2.5 \pm 0.5$ & $2.3 \pm 0.5$ & $2.5 \pm 0.4$ & 0.043 \\
TBW/FFM & $73.8 \pm 0.4$ & $74.0 \pm 0.4$ & $73.7 \pm 0.4$ & 0.004 \\
Phase angle $\left({ }^{\circ}\right)$ & $4.6 \pm 1.2$ & $4.0 \pm 1.0$ & $4.9 \pm 1.2$ & 0.002 \\
\hline
\end{tabular}

Note: All variables are expressed as mean \pm SD.

Abbreviations: $\mathrm{BCM}$, body cell mass; $\mathrm{BMC}$, bone mineral contents; $\mathrm{ECW}$, extracellular water; FFM, fat-free mass; ICW, intracellular water; SD, standard deviation; SLM, skeletal lean mass; SMM, skeletal muscle mass; TBW, total body water.

95\% CI: 0.021 to $0.567, P=0.035$ ), and $\mathrm{PhA}(\beta=-0.987,95 \%$ CI: -1.137 to $-0.837, P<0.001$ ) were independent risk factors for $\mathrm{ECW} / \mathrm{TBW}$, representative of hydration status, and $\operatorname{PhA}(\beta=-0.797,95 \% \mathrm{CI}:-1.373$ to $-0.220, P=0.008)$ was an independent risk factor for MIS, representative of nutritional status in total HD patients (Table 4).
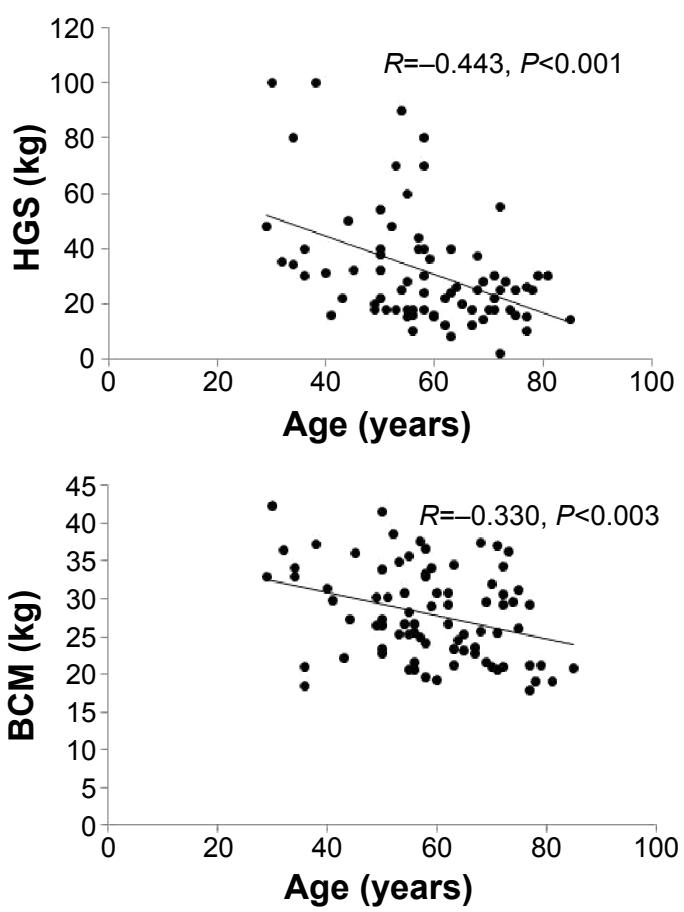

\section{Discussion}

The main findings of our study were as follows: 1) ICW, protein, mineral, SMM, BCM, BMC, and PhA were decreased in elderly HD patients; 2) ECW/TBW and TBW/FFM were higher in elderly HD patients; 3 ) older age, the presence of diabetes, and $\mathrm{PhA}$ were significant independent risk factors for increased ECW/TBW, representative of fluid overload, status in HD patients; and 4) PhA, measured by BIA, was the only independent predictor for MIS, representative of nutritional status in HD patients.

Recently, the importance of the hydration status in HD patients has been highlighted. Some studies have demonstrated that the fluid overload status is known to be an important and independent prognostic factor of mortality in chronic HD patients. ${ }^{5}$ Strict volume control and maintenance of a normal blood pressure increases the survival rate in HD patients. ${ }^{15,16}$ In daily clinical practice, volume status evaluations in HD patients have been traditionally based on clinical signs, such as changes in body weight, presence of pretibial edema, and blood pressure. However, this traditional method may lead to misinterpretations and is dependent on physicians' experience. ${ }^{17}$ The use of biomarkers, for example, $\mathrm{BNP}^{18}$ and inferior vena cava diameter, ${ }^{19}$ are either invasive or too expensive to implement in daily clinical practice. Dual energy X-ray absorptiometry (DEXA) scanning is also a useful method to evaluate hydration status in dialysis
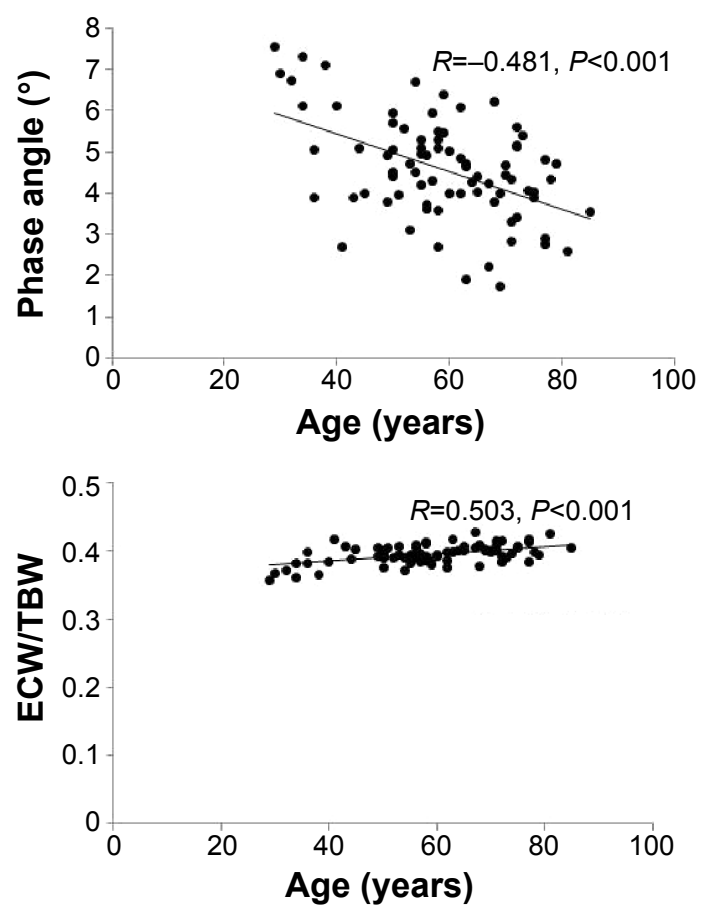

Figure I Pearson's correlation between age and various parameters in all HD patients.

Abbreviations: BCM, body cell mass; ECW, extracellular water; HD, hemodialysis; HGS, hand grip strength; TBW, total body water. 


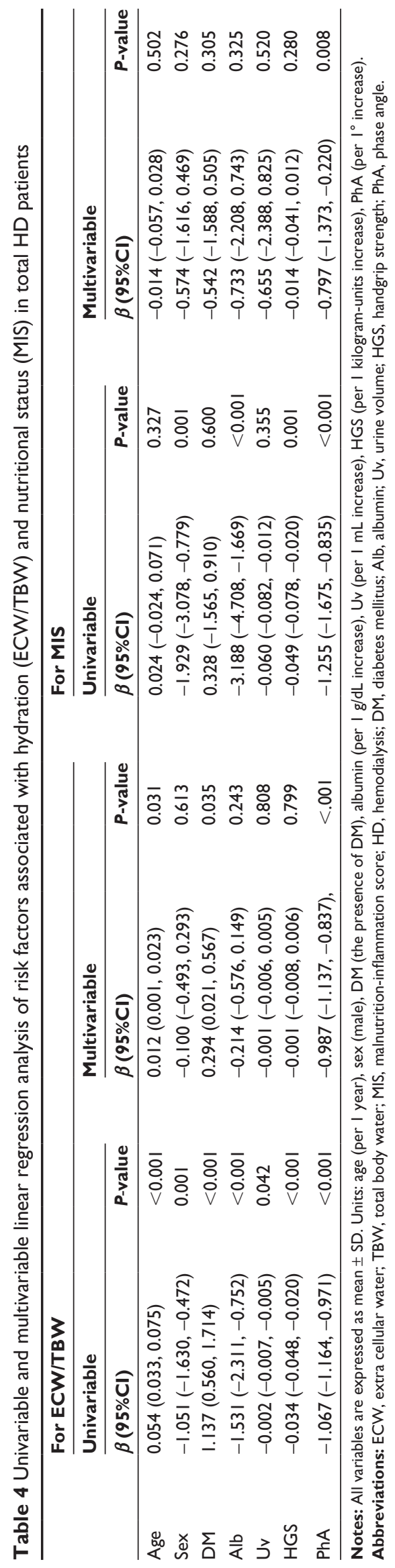

patients; however, its clinical usefulness is low because the DEXA estimations of FFM can be influenced by hydration status. ${ }^{20}$ Different from those methods, multifrequency BIA can measure the ECW and ICW volumes separately. In other words, BIA comprises a combination between the capacitance values created by the membranes and tissue boundary surface and resistance values for electric current through cells. ${ }^{21}$ Individual body composition can be measured by the components using these differences. Therefore, BIA has gained popularity in recent years and has been proposed as a noninvasive and reproducible tool for assessment of body composition in HD patients. ${ }^{9,22}$

Generally, human body composition is altered throughout the human life span by aging process. Among individuals, optimal body composition may vary, but higher FFM and lower fat mass are favorable for physical performance. ${ }^{23}$ During aging, fat mass increases steadily and body fat is redistributed as follows: subcutaneous fat decreases and visceral and intramuscular fat increases at the same time. ${ }^{24}$ Sillanpää et $\mathrm{al}^{25}$ reported that FFM, including lean body mass, decreases and fat mass increases after the fifth decade, when estimated by BIA. In the current study, we found that SMM, BCM, and BMC significantly decreased, and total FFM tended to decrease (but nonsignificantly), with age. This discrepancy may be explained by the fact that there were different characteristics between the general population and dialysis patients even if both groups were of older age.

Because the ECW/TBW ratio was previously used as an index of hydration, ${ }^{26}$ we also assessed the hydration status using this ratio. While ECW was similar between elderly HD patients and young HD patients, the ICW in elderly HD patients was significantly decreased compared with that in young HD patient. A possible explanation for this might be that ICW is decreased because the muscle mass decreases with age. This is also in accord with significantly lower BCM in elderly patients. We also found that ECW/ TBW significantly increased with age. This result may be explained by the fact that elderly HD patients have more fluid overload status and poorer nutritional status compared with young HD patients. Woodrow indicated that ECW/ TBW may be influenced by malnutrition, as well as by fluid overload status, because it includes ICW in the denominator. ${ }^{27}$ Thus, we recommend consideration of nutritional status when body water status is estimated by ECW/TBW in HD patients.

Malnutrition is commonly observed as a complication and a strong predictor of mortality in HD patients. ${ }^{28}$ MIS is a valid tool to evaluate the degree of malnutrition in ESRD patients. 
The current study showed that PhA was significantly correlated with MIS. This is in agreement with the findings of other studies, in which $\mathrm{PhA}$ was associated with the nutritional status, indicated by serum albumin, creatinine, subjective global assessment, and various anthropometric measures..$^{29,30}$ $\mathrm{PhA}$ is calculated as the arctangent of the directly measured reactance to resistance ratio and is independent of weight or height. ${ }^{14}$ Due to the association between PhA and most nutritional markers, it has a prognostic usefulness in HD patients. BCM is an another representative parameter of nutritional status ${ }^{8}$ that appears to be less influenced by variation in blood volume. Therefore it is a useful parameter for assessing the nutritional status in dialysis patients. Woodrow indicated that BCM is a more specific measure in the assessment of nutrition status than FFM and lean body mass, which include an ECF component and thus, change with the hydration status. ${ }^{27}$ However, our study did not show any significant correlation between BCM and hydration and nutritional status on multivariate analysis. It is possible that these discrepancies were due to different characteristics and sizes of the study populations.

HGS is a simple and reliable method to evaluate muscle function in dialysis patients as well as in the general population. ${ }^{31}$ Silva et al reported that HGS is a valid screening nutritional tool for malnutrition and inflammation in HD patients. $^{32}$ The current study showed that HGS was significantly lower in elderly HD patients compared with young HD patients. However, it was not an independent factor of malnutrition and fluid overload status in our multivariate analysis. This discrepancy could be due to the differences in patient characteristics (HGS in our study patients was higher than that in the patients in previous study). ${ }^{32}$ Therefore, our findings suggest that HGS was not a significant factor in assessing the nutritional status of HD patients compared with BIA. As HGS shows sex differences, we conducted multivariate analysis according to sex, and there were no significant relationships between HGS and ECW/TBW and MIS (data not shown).

Our study has several limitations. First, it was a crosssectional observational study and the sample size was small. However, post hoc power analysis showed a power of $9.36 \%$, which demonstrates that our results are statistically sound. Second, we did not check serum biomarkers, such as BNP levels. But, Agarwal reported that BNP was not a volume marker among hypertensive patients on HD. ${ }^{33}$ Also, the complete assessment including biochemical laboratory findings, MIS, HGS, and all BIA parameters strengthen the overall study results.
In conclusion, ICW was lower and $\mathrm{ECW} / \mathrm{TBW}$ was higher in elderly HD patients compared with young HD patients, which implied that elderly HD patients had greater fluid overload status. Therefore, we recommend that routine body composition analysis with BIA should be performed in elderly HD patients. We additionally recommend an improvement in the water distribution status of elderly HD patients because the nutritional status of these patients is poorer than in young HD patients, which may be further confounded by the water distribution status. Also, we found that $\mathrm{PhA}$ measured by BIA was a significant independent predictor of fluid overload status and malnutrition in HD patients. Therefore, our results indicated that BIA might be a clinically useful method for assessing the nutritional and hydration status in elderly HD patients. Further research with larger cohorts is needed to confirm our findings.

\section{Disclosure}

The authors report no conflicts of interest in this work.

\section{References}

1. Stevens LA, Viswanathan G, Weiner DE. Chronic kidney disease and end-stage renal disease in the elderly population: current prevalence, future projections, and clinical significance. Adv Chronic Kidney Dis. 2010;17(4):293-301.

2. Hung SC, Kuo KL, Peng CH, et al. Volume overload correlates with cardiovascular risk factors in patients with chronic kidney disease. Kidney Int. 2014;85(3):703-709.

3. Shotan A, Dacca S, Shochat M, Kazatsker M, Blondheim DS, Meisel S. Fluid overload contributing to heart failure. Nephrol Dial Transplant. 2005;20 Suppl 7:vii24-vii27.

4. Kayikcioglu M, Tumuklu M, Ozkahya M, et al. The benefit of salt restriction in the treatment of end-stage renal disease by haemodialysis. Nephrol Dial Transplant. 2009;24(3):956-962.

5. Wizemann V, Wabel P, Chamney P, et al. The mortality risk of overhydration in haemodialysis patients. Nephrol Dial Transplant. 2009; 24(5):1574-1579.

6. Palmer BF, Henrich WL. Recent advances in the prevention and management of intradialytic hypotension. J Am Soc Nephrol. 2008;19(1):8-11.

7. Fiedler R, Jehle PM, Osten B, Dorligschaw O, Girndt M. Clinical nutrition scores are superior for the prognosis of haemodialysis patients compared to lab markers and bioelectrical impedance. Nephrol Dial Transplant. 2009;24(12):3812-3817.

8. Hyun SH, Choi JY, Cho JH, Park SH, Kim CD, Kim YL. Assessment of fluid and nutritional status using multifrequency bioelectrical impedance analysis in peritoneal dialysis patients. Blood Purif. 2014;37(2):152-162.

9. Garagarza C, João-Matias P, Sousa-Guerreiro C, et al. Nutritional status and overhydration: can bioimpedance spectroscopy be useful in haemodialysis patients? Nefrologia. 2013;33(5):667-674.

10. Buffa R, Floris GU, Putzu PF, Marini E. Body composition variations in ageing. Coll Antropol. 2011;35(1):259-265.

11. van Biesen W, Claes K, Covic A, et al. A multicentric, international matched pair analysis of body composition in peritoneal dialysis versus haemodialysis patients. Nephrol Dial Transplant. 2013; 28(10):2620-2628.

12. Daugirdas JT. Second generation logarithmic estimates of single-pool variable volume Kt/V: an analysis of error. J Am Soc Nephrol. 1993; 4(5):1205-1213. 
13. Kalantar-Zadeh K, Kopple JD, Block G, Humphreys MH. A malnutritioninflammation score is correlated with morbidity and mortality in maintenance hemodialysis patients. Am J Kidney Dis. 2001;38(6):1251-1263.

14. Kyle UG, Bosaeus I, De Lorenzo AD, et al; ESPEN. Bioelectrical impedance analysis-part II: utilization in clinical practice. Clin Nutr. 2004;23(6):1430-1453.

15. Ozkahya M, Ok E, Toz H, et al. Long-term survival rates in haemodialysis patients treated with strict volume control. Nephrol Dial Transplant. 2006;21(12):3506-3513.

16. Saran R, Bragg-Gresham JL, Levin NW, et al. Longer treatment time and slower ultrafiltration in hemodialysis: associations with reduced mortality in the DOPPS. Kidney Int. 2006;69(7):1222-1228.

17. Vasko R, Müller GA, Ratliff BB, Jung K, Gauczinski S, Koziolek MJ. Clinical judgment is the most important element in overhydration assessment of chronic hemodialysis patients. Clin Exp Nephrol. 2013; 17(4):563-568.

18. Booth J, Pinney J, Davenport A. N-terminal proBNP - marker of cardiac dysfunction, fluid overload, or malnutrition in hemodialysis patients? Clin J Am Soc Nephrol. 2010;5(6):1036-1040.

19. Cheriex EC, Leunissen KM, Janssen JH, Mooy JM, van Hooff JP. Echography of the inferior vena cava is a simple and reliable tool for estimation of 'dry weight' in haemodialysis patients. Nephrol Dial Transplant. 1989;4(6):563-568.

20. Konings CJ, Kooman JP, Schonck M, et al. Influence of fluid status on techniques used to assess body composition in peritoneal dialysis patients. Perit Dial Int. 2003;23(2):184-190.

21. Kuhlmann MK, Zhu F, Seibert E, Levin NW. Bioimpedance, dry weight and blood pressure control: new methods and consequences. Curr Opin Nephrol Hypertens. 2005;14(6):543-549.

22. Basile C, Vernaglione L, Di Iorio B, et al. Development and validation of bioimpedance analysis prediction equations for dry weight in hemodialysis patients. Clin J Am Soc Nephrol. 2007;2(4):675-680.

23. Janssen I, Ross R. Linking age-related changes in skeletal muscle mass and composition with metabolism and disease. JNutr Health Aging. 2005; 9(6):408-419.
24. Zamboni M, Armellini F, Harris T, et al. Effects of age on body fat distribution and cardiovascular risk factors in women. Am J Clin Nutr. 1997; 66(1):111-115.

25. Sillanpää E, Cheng S, Häkkinen K, et al. Body composition in 18- to 88-year-old adults - comparison of multifrequency bioimpedance and dual-energy X-ray absorptiometry. Obesity (Silver Spring). 2014;22(1):101-109.

26. Inal S, Erten Y, Okyay GU, et al. Association between bioimpedance analysis parameters and left ventricular hypertrophy in peritoneal dialysis patients. Int Urol Nephrol. 2014;46(9):1851-1856.

27. Woodrow G. Extracellular water expansion: part of the malnutritioninflammation-atherosclerosis syndrome? Perit Dial Int. 2006;26(5): 566-570.

28. Rosenberger J, Kissova V, Majernikova M, Straussova Z, Boldizsar J. Body composition monitor assessing malnutrition in the hemodialysis population independently predicts mortality. J Ren Nutr. 2014; 24(3):172-176.

29. Oliveira CM, Kubrusly M, Mota RS, Silva CA, Choukroun G, Oliveira VN. The phase angle and mass body cell as markers of nutritional status in hemodialysis patients. J Ren Nutr. 2010;20(5):314-320.

30. Beberashvili I, Azar A, Sinuani I, et al. Bioimpedance phase angle predicts muscle function, quality of life and clinical outcome in maintenance hemodialysis patients. Eur J Clin Nutr. 2014;68(6):683-689.

31. Wang AY, Sea MM, Ho ZS, Lui SF, Li PK, Woo J. Evaluation of handgrip strength as a nutritional marker and prognostic indicator in peritoneal dialysis patients. Am J Clin Nutr. 2005;81(1):79-86.

32. Silva LF, Matos CM, Lopes GB, et al. Handgrip strength as a simple indicator of possible malnutrition and inflammation in men and women on maintenance hemodialysis. J Ren Nutr. 2011;21(3):235-245.

33. Agarwal R. B-type natriuretic peptide is not a volume marker among patients on hemodialysis. Nephrol Dial Transplant. 2013;28(12): 3082-3089.
Clinical Interventions in Aging

\section{Publish your work in this journal}

Clinical Interventions in Aging is an international, peer-reviewed journal focusing on evidence-based reports on the value or lack thereof of treatments intended to prevent or delay the onset of maladaptive correlates of aging in human beings. This journal is indexed on PubMed Central, MedLine,

\section{Dovepress}

CAS, Scopus and the Elsevier Bibliographic databases. The manuscript management system is completely online and includes a very quick and fair peer-review system, which is all easy to use. Visit http://www.dovepress. com/testimonials.php to read real quotes from published authors. 